\title{
İlköğretim Matematik Öğretmenlerinin Öğretim Teknolojilerine Bakış Açısı
}

\author{
DOI: 10.26466/opus.620980
}

*

\author{
Ebru Korkmaz* \\ * Dr. Öğr. Üyesi, Muş Alparslan Üniversitesi, Eğitim Fakültesi, Muş / Türkiye \\ E-Posta: eb.korkmaz@alparslan.edu.tr \\ ORCID: $\underline{0000-0001-6250-3293}$ \\ Öz
}

Bu çalışmada, ilköğretim matematik öğretmenlerinin öğretim teknolojisine bakıs açıları, öğretim teknolojilerini kullanabilirlikleri ve öğretim teknolojisinin faydalar incelenmiştir. Veri toplama aracı olarak yarı yapılandırılmış mülakat formu kullanılmıştır. Veriler 2018-2019 eğitim-öğretim yılında Doğu Anadolu bölgesinde yer alan bir il merkezi ilköğretim okullarında görev yapmakta olan 24 ilköğretim matematik öğretmeninden elde edilmiştir. Yapılan analiz sonrasi; verilen hizmet içi eğitim kurslarının, öğretmenlerin kendi imkânları doğrultusunda edindikleri bilgilerin, internet erişimli akıllı tahta kullanımının, geogebra gibi çeşitli yazllımların faydalı olduğu görülmektedir. Ayrıca öğretmenlerin büyük bir kısmı, kullanılan öğretim teknolojilerinin matematik dersine yönelik kavram yanılgılarını ortadan kaldırabileceğini ifade etmiştir. Bununla birlikte birçok matematik öğretmeni kullanılan teknolojilerin dersin işlenişinde ve müfredat ile paralel olarak konuların yetiştirilmesinde büyük kolaylık sağladığını belirtmiştir. Ayrıca birçok öğretmenin Geogebra yazılım programı ve akıllı tahtanın yanı sıra farklı yazılımlarda da eğitim almak istediği tespit edilmiştir. Buna karşın öğretim teknolojilerine yönelik herhangi bir eğitim almamışöğretmenlerin teknoloji kullanmada güçlük yaşadığg ve kendilerini yeterli düzeyde hissetmedikleri, ayn okulda 4 yıl üzeri görev yapan öğretmenlerin de geleneksel yöntemlerden vazgeçmekte zorlandığı görülmüş̧ür.

Anahtar Kelimeler: $\quad$ Matematik Öğretimi, Öğretim Teknolojisi, Akıllı Tahta, Yazılım 


\title{
Elementary Mathematics Teachers' Perspectives on Instructional Technologies
}

\begin{abstract}
In this study, elementary school mathematics teachers' perspectives on instructional technology, their use of instructional technologies and the benefits of instructional technology were examined. A semistructured interview form was used as a data colletion tool. The data were obtained from 24 mathematics teachers working in central elementary schools in a province in Eastern Anatolia at 2018-2019 academic year. After the analysis; it is seen that the in-service training courses provided, the information acquired by the teachers according to their own means, the use of smart board with internet access, geogebra and various software are beneficial. In addition, most of the teachers stated that the usage of instructional technologies could eliminate misconceptions about mathematics lesson. Also, many mathematics teachers expressed that the technologies used in mathematics teaching provide great convenience in parallel with the curriculum in the course. On the other hand, it was seen that teachers who did not receive any training in instructional technologies had difficulty in using technology and did not feel themselves sufficiently. Furthermore, it was determined that the teachers want to get education in different software besides geogebra software program and smart board. On the other hand, it was observed that teachers who did not have sufficient education on instructional technologies had difficulties in using technology and did not feel efficient themselves, and teachers who worked in the same school for more than 4 years had difficulty in giving up traditional methods.
\end{abstract}

Keywords: Maths teaching, Instructional technology, Smart board, Software 


\section{Giriş}

Gelişmekte olan dünyamızda bilgi teknolojisinin her alanında ilerlemeler, değişiklikler ve yenilikler yaşanmaktadır. Bu gelişmelerden eğitimin de etkilenmemesi hemen hemen kaçınılmazdır (Akkoyunlu, 1995). Ayrıca öğrencilerde matematik yeterliliğini geliştirmek tüm okullar için önemli bir hedef haline gelmektedir (Ball, 2003). Teknolojinin matematik eğitimini etkilemesi sonucu öğrencilerin gelişimi artmakta, dolayısıyla da teknoloji matematiği öğrenme ve öğretmede bir gereklilik olarak görülmektedir (Leinwand ve Burrill, 2002). Öğrencilerin daimi belleklerinin nasıl geliştirileceğinden çok öğrencilerin nasıl destekleneceği matematik öğretiminde sorulması gereken en temel sorulardan biri olmalıdır. Yeni bir problemle karşılaşan bireyin, problemi çözmek için hangi matematiksel kuralları kullanacağını bilmede ve nasıl uzmanlaştıklarını anlamada uzun bir süreçte kazanılan algılarından ziyade bilgi ile girmiş oldukları etkileşim önemli bir rol oynar. Bilmeye ve öğrenmeye odaklanıldığında, matematik sınıflarında kurulan öğretim uygulamaları büyük önem taşımaktadır (Gresalfi ve Lester, 2009, s.265, 268-269).

Eğitim kurumlarında önceden tasarlanmış hedef, düzen ve sistemli bir plan dâhilinde sürdürülen faaliyetlere öğretim denilmektedir (Güneş, 2014). Bununla birlikte teknoloji belirli hedeflere varmada, belirli problemlere çare bulmada, gözlenebilen ve ispatlanabilen bilgilerde kullanılmaktadır (Demirel, 1993). Öğretim teknolojisi, öğretim problemlerinin çözümünü bulmak amacıyla davranıs bilimleri ile fen bilimlerinin yapısından ve daha farklı bilgilerden harmanlanan programlı-düzenli yöntemlerin bir uygulanması olarak tanımlanabilir (Kaya, 2006). Dolayısıyla öğretimdeki problemlerin bilimsel kuramlarla ilişkili olarak ne şekilde bir çözüme ulaşılabileceğini ele alan ve belirleyen yardımcı araca öğretim teknolojisi denebilir. McRel (2012, s.269)' e göre ise öğretim teknolojisi; sınıf içi öğreniminde öğrenciyi teşvik etmek için kullanılan araç gereçleri ifade eder. Matematik öğretiminde genellikle problem çözmede öğretim teknolojisi kullanılır. Böylece öğrenme deneyimleri öğrenci merkezli olarak gerçekleşir. Kullanılan belirli teknolojiler arasında hesap makineleri, elde taşınır veri toplama aygıtları, bilgisayarlar gibi çeşitli yazılım-donanım türleri ve internet bulunmaktadır.

Öğretim teknolojilerini günümüz şartlarına uygun bir şekilde eğitimde kullanmak gerekmektedir. Buradaki büyük sorumluluk öğrencilerin yönlen- 
diricisi olan ve bilgi aktaran öğretmenlere düşmektedir. Öğretmen, karatahtadan internetteki çeşitli yazılım programlarına kadar birden fazla araç-gereci kullanabilecek düzeyde olmalıdır (Tor ve Erden, 2004). Kullanılan öğretim teknolojileri ile öğrencilerin ilgi düzeyi ve katılımları artmaktadır. Matematik dersinde kullanılan öğretim teknolojilerinin diğer faydaları arasında; veri toplama ve grafik oluşturmadaki objektiflik, huz; gerçek zamanlı görselleştirme; belirsiz matematiksel süreçlerin etkileşimli olarak modellenmesi; büyük miktarda veri toplayabilme, kolay hesaplama ve analiz edebilme yeteneği; veri toplama ve yorumlamadaki işbirliği; ve sonuçlardaki sunum yöntemlerini değiştirmek için daha fazla fırsat sunması gibi özellikler sayılabilir. Ayrıca teknoloji, tüm öğrenciler için matematiği daha anlamlı hale getirebilmektedir (McRel, 2012).

21. yy. başları itibariyle gerek değişen öğretim programı gerekse yapılandırmacı yaklaşımın gerekleri doğrultusunda öğrenci merkezli ve düşündürmeye, buldurmaya önem verilmeye başlanmaktadır. Eğitim sistemimizde MEB' in uygulamaları ile birlikte teknolojik faaliyetler kazanımlarda yer almaya başlamıştır. Öğrencilerin soyut düşünebilmeleri, analiz edebilmeleri ve ihtiyaçların karşılayabilmeleri için teknoloji destekli öğretimlere yer verilmiştir. Üniversitelerde verilen teknolojik esaslı dersler ve hizmet içi kurslarda buna yönelik eğitim alan öğretmenlerin daha donanımlı ve yeterli olduğunu göstermiştir. Sonuç olarak öğrencilerin bilgilerini pekiştirmelerinde, anlayıp yorumlamalarında teknoloji etkisi kaçınılmaz hale gelmektedir (Baki, 2002).

Kabul edilebilir ki eğitimde farklılaşmanın ve ilerlemenin olması için birçok etkene ihtiyaç vardır. Bu etkenlerin en önemlilerinden biri öğretimi başlatan ve şekillendiren öğretmenlerdir. Öğretmenlerin eğitim ve öğretim süresince gelişmekte olan teknolojiyi takip edip gerisinde kalmadan kendilerini geliştirmeleri ve öz yeterlik algısına sahip olmaları gerekmektedir (Oral, 2004). Günümüzde artık öğretmenlerin hem teknolojiyi yeterli düzeyde kullanabilir hem de bu teknolojileri öğrenme-öğretme aşamasında istenilen düzeyde uygulayabilir olması gerekmektedir (Gündüz ve Odabaşı, 2004). Bunun için de öğretmenlerin hevesli ve keşfetmeye meraklı olması gerekmektedir. Fakat öğretimi gerçekleştiren öğretmenlerin gerek kara tahtadan akıllı tahtaya geçme aşamasında gerekse farklı yazılımları kullanabilmede zorluk çekmeleri normaldir. Bu zorlukların çözümlenmesinde büyük payı olduğu kabul edilen teknoloji, bilimsel araştırmalar, teorik izahlar ile öğretmenlerin denk geldikleri problemler arasında bir köprü vazifesi görmektedir (Koşar, 
Yüksel, Özkılıç, Avcı, Alyaz ve Çiğdem, 2003). Bu köprünün, öğretimi ilgilendiren kısmında bulunan öğretim teknolojilerinin ise öğrenme sürecinin kalitesini artırdığı, öğretmeni aktif kıldığı, öğrencilerin ve öğretmenlerin istenilen amaçları elde etmek için kullandıkları vakti azalttığı, kaliteyi azaltmadan eğitimi ekonomik kıldığı, öğrenciyi süreçte aktifleştirdiği gibi faydalar sağladığı kabul edilmektedir (Öğ̈̈t, Altun ve Koçer, 2003).

İlkokul ve ortaokul, öğrencilerin matematik öğrenmeye teşvik edildikleri ve aynı zamanda matematiğin öneminin kazandırıldığı bir zamandır. Küçük çocukların rakamlarla ilgili maceralardan hoşlanıp, şekillerle oynamayı sevmeleri öğretilen matematiği sevdiklerinin bir göstergesidir. Ayrıca, okul günlerini dolduran matematiksel sayısız organize faaliyetler matematik öğrenimi ile ilgili bağlantı kurmalarına da yardımcı olmaktadır. "Üç takıma ayrılalım, topu açılandıralım, maket adama vurun, köşegen boyunca ilerleyin, kütlenin yüzdesini bulun" vb. karşılaşılan faaliyetler sayesinde öğrenciler matematiksel bağlantıları kurup anlamlandırabilirler (Kanold, Briars ve Fennel, 2012, s.1). Öğrencilerin kendilerini geliştirmek için ilgi çekici, teşvik edici ve zenginleştirici bir öğrenme ortamına ihtiyaçları vardır (Stronge, 2013, s.65). 2001 yılında Çin' de gerçekleştirilen müfredat reformu sayesinde öğrenciler geleneksel matematik sınıfları yerine zengin kaynaklı, teknolojik sınıflarda yapılandırmacı yöntem ile hazırlanan matematik sınıflarında öğretim görmeye başlamışlardır (Rui ve Ngai-ying, 2013, s.356-358).

İnsan ve bilgisayar arasındaki etkileşime yol açan teknoloji, kişinin bilgisayarla ilgili deneyimiyle birlikte belirli bir konu veya öğeyle nasıl etkileşim kurduğuna dayanır. Kullanıcıların bilgisayar veya farklı teknolojilerle etkileşime girmesi, içinde bulunulan durum düşünce ve teknolojiye duyulan ihtiyacı etkilemektedir. Teknolojinin temeli, insanların teknoloji ile uyumu insan ve bilgisayar arasındaki etkileşim ile belirlenebilir. Hem mesleki hem de sosyal yaşantı açısından yaşanan farklı koşul ve faaliyetler öğretmenlerin matematik dersinde teknoloji entegrasyonuna yönelik temelini oluşturur. Öğretmenlerin teknolojiyle ilgili duygu ve düşüncelerini belirlemek için geleneksel öğrenme ile etkinlik temelli öğrenme yaklaşımlarının değerlendirilmesi gerekir (Brown, 2017). 


\section{Çalışmanın Önemi}

MEB Öğretmen Yetiştirme ve Geliştirme Genel Müdürlüğü günümüzde yaşanan teknolojik değişim ve gelişmelere ayak uydurma aşamasında yeterli istek ve uğraşta bulunması gereken öğretmenlerin görevlerinin farklılaştı̆̆ını ifade etmektedir. Bu görevler arasında öğretmenlerin yeni öğretim teknolojilerini kabul etme ve kullanabilme konusunda esnek olmaları, öğretimde yeniliklere açık olmaları gerektiği yer almaktadır (Varol, 2002). Anlaşılacağı üzere öğretmenlerin ilk adımda teknolojiyi tanıma, benimseme ve ardından kullanabilmeleri gerekmektedir. Gündüz ve Odabaşı (2004)' nın belirttiği üzere günümüzde öğretmenler teknolojiden aktif bir şekilde yararlanabilmeli, yeteneklerini kullanıp bu teknolojileri öğretim aşamasında kaliteli bir şekilde kullanabilmelidirler. Öğretmenlerin, belirlenen amaç doğrultusunda teknolojinin sağladığı imkânlardan daha aktif faydalanmaları için teknoloji hakkındaki düşünceleri fazlasıyla değerlidir (Çelik ve Kahyaoğlu, 2007). Bu çalışma öğretmenlerin öğretim teknolojilerine yönelik düşünce, tutum, karşılaştıkları sorunları ve çözüm önerilerini içermesi açısından önem arz etmektedir.

\section{Araştırmanın Amacı}

Teknolojideki yenilikler ve gelişmeler her toplumda ve ülkede yalnızca bir gereklilik olmamakla birlikte toplumun gelişimini ve ilerleyişini sağlamaya yarayan büyük bir ihtiyaç haline gelmiştir. Alışılagelmiş öğretmenlik mesleği, karatahta önünde öğretmen merkezli olup geleneksel bir eğitimden öteye gidememiştir. Nitekim özellikle matematik dersinde konuların ve geometrik kavramların soyut olması öğretmen ve öğrenciler için güçlüklere neden olabilmektedir. Geleneksel eğitimden çağdaş eğitime geçtiğimiz son yıllarda teknolojinin hızlı gelişimi ile birlikte öğretim teknolojilerine olan ihtiyaç artmış olup mevcut yenilikler kendini eğitim alanında da göstermeye başlamıştır. Bu çalışmanın amacı ilköğretim matematik öğretmenlerinin öğretim teknolojilerine yönelik farkındalıklarını belirlemektir. 


\section{Yöntem}

\section{Araştırma Deseni}

Gerçekleştirilen bu çalışmada hedeflenen şey, araştırılan konuyu derinlemesine incelemek, izah etmek, kriterler etrafında gözden geçirmek ve ortaya ç1kan olguları değerlendirip kanıya varmak olduğundan betimsel yaklaşım kullanılmıştır (Çepni, 2007).

Çalışmadan elde edilen verileri incelemek için betimsel yaklaşım boyutunda durum çalışması deseni kullanılmıştır. Çalışmada bu desenin kullanılmasının sebebi; ele alınan problem durumunun birçok özelliğini ayrıntılı bir şekilde ve en az zamanda çalışılmasına olanak sağlamasıdır (Yin, 2003; Çepni, 2007).

\section{Çalışma Grubu}

Tablo 1. Araştırmaya katılan öğretmenlerin demografik özellikleri

\begin{tabular}{|c|c|c|}
\hline Öğretmen & Cinsiyet & Görev Süresi \\
\hline 1 & Kadın & $1-3$ yil \\
\hline 2 & Erkek & $4-6$ yil \\
\hline 3 & Erkek & $1-3$ yil \\
\hline 4 & Kadın & $1-3$ yil \\
\hline 5 & Kadın & $4-6$ yil \\
\hline 6 & Erkek & $1-3$ y1l \\
\hline 7 & Kadın & $1-3$ yil \\
\hline 8 & Erkek & 7 yıl üzeri \\
\hline 9 & Kadın & $1-3$ yil \\
\hline 10 & Kadın & 7 yıl üzeri \\
\hline 11 & Kadın & $1-3$ yıl \\
\hline 12 & Erkek & $4-6$ yil \\
\hline 13 & Kadın & $1-3$ yil \\
\hline 14 & Erkek & $4-6$ y1l \\
\hline 15 & Erkek & 7 yıl üzeri \\
\hline 16 & Erkek & 7 yıl üzeri \\
\hline 17 & Erkek & 7 yıl üzeri \\
\hline 18 & Kadın & $4-6$ yil \\
\hline 19 & Erkek & 7 yıl üzeri \\
\hline 20 & Kadın & $1-3$ yıl \\
\hline 21 & Erkek & $4-6$ yil \\
\hline 22 & Kadın & $1-3$ yil \\
\hline 23 & Kadın & $1-3$ yil \\
\hline 24 & Kadın & $4-6$ yil \\
\hline
\end{tabular}


Yapılan çalışmanın örneklemini Doğu Anadolu'da bir il merkezi ilköğretim okullarında görev yapmakta olan 24 ilköğretim matematik öğretmeni oluşturmaktadır. Ortam, kültür, sosyo-ekonomik düzey vb. özelliklerin göz önünde bulundurulması neticesinde çalışma grubunun oluşturulmasında farklı okullar esas alınmıştır. Ayrıca çalışma grubunu oluşturan 24 öğretmen gönüllülük esasına göre seçilmiştir. Çalışma grubunda yer alan öğretmenlerin 11' i erkek, 13'ü kadın olup bulunduğu okuldaki görev süresi 1-3 yıl arası olan 11 öğretmen, 4-6 yıl arası olan 7 öğretmen, 7 yıl ve üzeri olan 6 öğretmen bulunmaktadır. Çalışma grubunun görev sürelerinin belirlenmesinde kullanılan ilk 3 yıl aralığı; öğretmenlerin bulunduğu okuldan görev yeri değişiklik hakkının en az 3 yıl sonra elde edilebilmesinden kaynaklanmaktadır.

\section{Veri Toplama Aracı ve Analizi}

Bu çalışmada veri toplama aracı olarak Baki, Aydın, Özpınar ve Çalık (2009)'ın hazırlamış olduğu yarı yapılandırılmış mülakat formu kullanılmıştır. Yarı yapılandırılmış bu mülakat formundaki sorulara Ek 1' de verilmiştir. $\mathrm{Bu}$ formun geçerliğini sağlamak için araştırma kapsamı dışında form 4 öğretmene uygulanarak gerekli görülen yerlerde düzeltmeler yapılmıştır. Öğretmenlere uygulanan mülakat formu ortalama 20-25 dk. sürmüştür. Elde edilen veriler Ö1, Ö2, ..., Ö24 şeklinde kodlarla işaretlenip öğretmenlerin her bir soruya yönelik yanıtları gözden geçirilerek benzer olan ve benzer olmayan veriler özetlenerek ve yorumlanarak Tema, Kategori, Kod ve Frekanslar başlıklarında belirlenmiştir. Verilerin analizinde betimsel bir yaklaşımla içerik analizi kullanılmıştır (İşçi ve Öztekin, 2013; Yıldırım ve Şimşek, 2011). Ayrıca verilerin analizi iki araştırmacı tarafından önceden tartışlarak görüş birliği dahilinde gerçekleştirilmiştir. Elde edilen veriler kodlara ve temalara göre düzenlendikten sonra doğrudan alıntılara yer verilmiştir. Temalar altındaki kodların öğretmen tarafından ne kadar sıklıkla ifade edildiği " $x$ " işareti ile belirtilmiştir. Kodlar bir araya getirilerek tablolaştırılmıştır ve sıklıkları belirtilerek yorumlanmıştır. Kodlayıcılar arasında görüş birliğinin ortaya konması için yapılan güvenirlik çalışmasında; Kodlayıcılar arası görüş birliği/ayrilığı Miles ve Huberman (1994)'́n,

Güvenirlik $=\frac{\text { görüss birliği }}{\text { görüş birliği+görüs ayrllı̆̆l }} \times 100$ formülünden yaralanılarak hesaplanmıştır. \% 60 görüş birliğini sağlayan maddeler aynen kabul edilirken, 
görüş ayrilığı bulunan ya da \%60'ın altında kalan maddeler üzerinde araştırmacılar tarafından tartışılarak ikinci kez uzman görüşü alınmıştır. İkinci uzman görüşünde ise \% 80 görüş birliği hedeflenmiştir. Turner ve Carslon (2003) değişen bir ölçüt olmakla beraber 0,75 ve daha büyük ortalamanın uzmanlar arası görüş birliğini gösterebileceğini belirtmişlerdir. Çalışmanın veri analizinde kodlayıcılar arası görüş birliği \% 85 olarak hesaplanmıştır.

\section{Bulgular}

Bu bölümde ilköğretim matematik öğretmenlerinin öğretim teknolojisine yönelik bakış açıları incelenmiştir. Araştırma kapsamında öğretim teknolojisine yönelik elde edilen bulgular tabloda sunulmuştur.

Tablo 2. Öğretim teknolojisi kavramına yönelik öğretmen görüşleri

\begin{tabular}{|c|c|c|c|}
\hline Tema & Kod & $\mathbf{N}$ & $\mathrm{f}$ \\
\hline \multirow{7}{*}{ 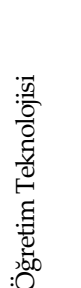 } & $\begin{array}{l}\text { Etkin eğitim için kullanılan araç-gereçler (EBA, } \\
\text { Fatih projesi, Akıllı tahta) }\end{array}$ & $\begin{array}{l}\text { Ö1, Ö2, Ö3, Ö7, Ö8, Ö9, Ö11, } \\
\text { Ö15, Ö16, Ö17, Ö18, Ö22 }\end{array}$ & 12 \\
\hline & Teknolojinin eğitime uyarlanması & Ö14, Ö19, Ö20, Ö21, Ö24 & 5 \\
\hline & Dersin kolay anlatılması & Ö4, Ö6 & 2 \\
\hline & Kalıcı öğrenme & Ö10, Ö12 & 2 \\
\hline & Planlı etkinlikler & Ö13 & 1 \\
\hline & Farklı duyulara hitap etme & Ö5 & 1 \\
\hline & Modern öğretim yaklaşımları & Ö23 & 1 \\
\hline
\end{tabular}

Öğretim teknolojisinden ne anladıklarına yönelik sorulan soruya öğretmenlerin vermiş oldukları bazı cevaplara aşağıda yer verilmiştir.

- Ö7. Eğitimi iyileştirmek öğretimi faydalı ve kalıcı hale getirmek için kullanlan teknoloji anlamina gelmektedir. Günümüz teknolojisinin bu denli yükselmesi ile öğretimden ayrn düşmesinin imkânsız olduğunu ve eğitimle içiçe olup yüksek öneme sahip olduğunu düşünüyorum.

- Ö9. Öğretim; öğrenmede yol gösteren bir kavram iken öğretim teknolojisi; yol gösteren bu kavrama yardımcı olan araç ve gereçlerdir.

- Ö3. Üretimi gerçekleştiren duyu organlarına fazlasıyla hitap eden ve öğrenimi daha etkin kılan çeşitli teknolojik araçlardır. Akıllı tahta, bilgisayar, EBA ve Fatih projeleri gibi.

- Ö14. Günümüz şartlarında gelişen teknolojinin eğitime uyarlanmış halidir.

- Ö23. Sunum ve görselliğin bol kavramsal yanilgzları ortadan kaldıran kolaylaştıran yeniçă̆ yöntemidir. 
Tablo 3. Öğretmenlerin kullanabildikleri yazılım ve donanımlar

\begin{tabular}{lll}
\hline Sıra & Donanımlar ve Yazılımlar & $\mathrm{f}$ \\
\hline 1 & Bilgisayar & 24 \\
2 & Internet & 23 \\
3 & Akıllı Tahta & 22 \\
4 & Kitap ve Dergi & 21 \\
5 & Video & 21 \\
6 & Kara Tahta & 20 \\
7 & Yazılımlar (Geogebra, Cabri vb.) & 16 \\
8 & Projeksiyon & 16 \\
9 & Hesap Makinesi & 16 \\
10 & Ses Kayıt Cihazı & 16 \\
11 & Tepegöz & 13 \\
12 & CD & 13 \\
13 & Episkop & 1 \\
\hline
\end{tabular}

Tablo 3’ te görüldüğü üzere öğretmenler tarafından en çok kullanılan öğretim teknolojileri bilgisayar, internet, akıllı tahta, video, kara tahta, kitap ve dergidir.

Öğretmenlerin öğretim teknolojilerine yönelik düşünceleri incelendiğinde hemen hepsinin öğretim teknolojilerini gayet yararlı gördükleri ve bu teknolojilerin kullanılması gerektiğine yönelik bilgiye ulaşılmıştır. Öğretim teknolojilerini kullanma konusundaki yararlara yönelik görüşler Tablo $4^{\prime}$ te verilmiştir.

Tablo 4. Öğretim teknolojilerinin kullanımının etkileri

\begin{tabular}{|c|c|c|c|c|}
\hline Tema & Kategori & Kod & $\mathbf{N}$ & $\mathrm{f}$ \\
\hline \multirow{12}{*}{ 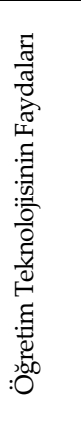 } & & Aktarım kolaylı̆̆ & Ö1,Ö2,Ö3,Ö4,Ö5,Ö8,Ö15,Ö16,Ö18,Ö22 & 10 \\
\hline & & Somutlaştırma & Ö1,Ö2,Ö3,Ö6,Ö8,Ö9,Ö13,Ö14,Ö24 & 9 \\
\hline & & Etkili öğretim-kalıcılık & Ö1,Ö5,Ö7,Ö8,Ö9,Ö11,Ö12,Ö13,Ö14 & 9 \\
\hline & & Zamandan tasarruf & Ö1,Ö2,Ö4,Ö5,Ö6,Ö13,Ö14,Ö20 & 8 \\
\hline & & Farklı duyular & Ö1,Ö5,Ö12,Ö14,Ö18,Ö19 & 6 \\
\hline & & Dikkat çekicilik & Ö3,Ö6,Ö7,Ö9 & 4 \\
\hline & & Eğlence & Ö2,Ö3,Ö6 & 3 \\
\hline & \multirow{3}{*}{ Var } & Katılım artışı-motivasyon & Ö11,Ö13 & 2 \\
\hline & & Bireysel öğrenme ortamı, keşif & Ö13,Ö23 & 2 \\
\hline & & Günlük hayattan örnek & Ö4 & 1 \\
\hline & \multirow[t]{2}{*}{ Yok } & Gelenekselcilik & Ö17 & 1 \\
\hline & & Faydasız & Ö21 & 1 \\
\hline
\end{tabular}

Tablo 4 ele alındığında, ilköğretim matematik öğretmenleri çoğunlukla öğretim teknolojilerinin; eğitim ve öğretimi kolaylaştırdığı, zamandan tasar- 
ruf sağladığı, konuları somutlaştırmaya yarar sağladığı, kullanışlılık açısından rahat olduğu ve etkili öğretimi sağladığını ifade etmişlerdir. Aşağıda öğretmen görüşlerinden bir kısmı verilmiştir.

- Ö9. Öğrenmeyi daha somut hale getirmek ve kahıılığı arttırmak gibi faydalar vardır. Günümüz teknoloji çă̆ı olduğu için öğretim teknolojilerini kullanmak daha ilgi çekici olmaktadır.

- Ö12. Öğrenmenin kahcı olması için daha fazla duyuya hitap etmesi gerekmektedir. Öğretim teknolojileri ile daha fazla duyuya hitap edilereköğrenme kahıı olur. Bunun için etkileşimli program ve yazılımlar bence en etkili olanlardır.

- Ö5. Öğretimin süresini azaltmaktadır. Daha az vakitte daha fazla bilgi verilmektedir. Farklı duyu organlarma hitap ettiğinden öğretimi daha kalıcı ve etkin kllmaktadır. Geometri gibi çizim gerektiren derslerden vakit kazanılmaktadır. Geogebra gibi yazılım programlarn ile 3 boyutlu geometrik cisimlerin anlatım daha da kolaylaşmaktadır. Bilgisayarm birçok özelliğinden yararlanarak görsel ve işitsel olarak ögrenci daha da etkin olmaktadır.

- Ö16. Dersin işlenişinde daha fazla şeyi öğrenciye göstermemizi sağhlyor. Yerinde kullanıldığında çok iyi oluyor ama çoğu zaman okulda kullanım amactnın dışına çıkılmaktadır.

- Ö11. Dersin daha etkili işlenmesi, kalıılığı, ilgi çekiciliği ve sımıfın katılım oranı açısından faydah olduğunu düşünüyorum.

- Ö23. Buluş yolunu canlandiran keşfetmeye yarayan bir yöntemdir.

Olumlu görüşlerin yanı sıra öğretim teknolojilerini faydalı bulmayan 2 öğretmen bulunmaktadır. Ö17'nin 7 yıl ve üzeri, Ö21' in de 4-6 y1l arası görev süresinin olduğu görülmektedir. Aynı okulda 4 yıldan fazla görev yapan her iki öğretmenin de öğretim teknolojilerine sıcak bakmama nedenlerini geleneksel öğretim yöntemlerine duyulan güven ve alışkanlıklardan vaz geçememe olduğunu düşündürmektedir.

- Ö21. Bazı konular için elbette ki faydah olabilir fakat genelde faydalı bulmuyorum.

- Ö17. Ben gelenekselciyim yüz yüze etkileşimden yanayım. Kalem kağıt ve kara tahta yeterlidir.

Öğretmenlerin öğretim teknolojileri konusunda karşılaştıkları güçlüklere yönelik düşüncelerini gösteren tablo aşağıda verilmiştir. 
Tablo 5. Öğretim teknolojilerinin kullanımında yaşanılan sorunlar

\begin{tabular}{|c|c|c|c|}
\hline Tema & Kod & $\mathrm{N}$ & $\mathrm{f}$ \\
\hline \multirow{11}{*}{ 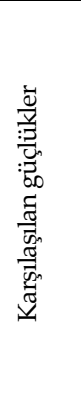 } & Bilgi eksiklikleri & Ö2,Ö4,Ö7,Ö13,Ö14,Ö19 & 6 \\
\hline & Elektrik kesintisi & Ö1,Ö2,Ö5,Ö20 & 4 \\
\hline & Bakım-denetim & Ö3,Ö5,Ö18,Ö19,Ö24 & 5 \\
\hline & İnternet & Ö9,Ö10,Ö15,Ö17 & 4 \\
\hline & Materyal eksikliği & Ö13,Ö14,Ö17 & 3 \\
\hline & Amaç dışı kullanım & Ö16,Ö19,Ö22 & 3 \\
\hline & Güncellenme & Ö2,Ö23 & 2 \\
\hline & Virüs & Ö1 & 1 \\
\hline & Kazanımlara yönelik teknoloji & Ö12 & 1 \\
\hline & Yazilım-donanım & Ö8 & 1 \\
\hline & Not tutmama & Ö21 & 1 \\
\hline
\end{tabular}

Tablo 5 incelendiğinde Ö1, Ö2, Ö5, Ö20 elektrik kesintisinin çok olduğunu, Ö2, Ö23 akıllı tahtanın güncellenme süresinin uzun olduğunu, Ö3, Ö5, Ö18, Ö19, Ö24 akıllı tahtaların bakım-denetiminin yeterince yapılmadığını belirtilmiştir. Ö2, Ö4, Ö7, Ö13, Ö14, Ö19 öğretim teknolojilerini kullanırken mevcut bilgi eksikliği, tecrübesizlik gibi nedenlerle kendilerini yetersiz buldukların ifade etmişlerdir. Ayrıca bu konu ile ilgili başka görüşlere de aşağıda yer verilmiştir.

- Ö12. Her konuya veya her kazanıma uygun öğretim teknolojisi olmayabilir, bu en sık karşılaşılan güçlüktür. Aslında bunu aşmak için de öğretmenlere programlama ve yazılım dersleri verilerek bu konularda kendi öğretim teknolojilerini, oyunlarını oluşturmaları săglanabilir.

- Ö7. Bazı teknolojileri kullanırken eksik bilgiye sahip olmak

- Ö1. Akıllı tahtaların elektrik kesiminden dolayı devaml kullanılamaması, Akıllı tahta ve bilgisayarlara virüs bulaşması karşılaşılan güçlükler arasındadır.

- Ö8. Yazılım veya donanımlarm istenilen güncellikte olmamasıdır. Teknik altyapr yetersizliği mevcuttur.

- Ö15. Öğretmenlerin teknolojik ürünlerin kullanımı konusunda kendilerini yeterince geliştirmemeleri kendileri için sıkıntı oluşturuyor. Bizim karşılaştı̆̆ımız zorluk ise simıflarda internet yok. Bu yüzden akull tahtalar kullanılamiyor.

- Ö19. Materyallerin amacinın dışında kullanılması, tablet veya akıllı tahtaların çalışmaması veya bozuk olması, onarlması gereken materyaller için yeterli teknik ekibin bölgede olmaması, öğretmen ve öğrencilerin yeterlibilgiye sahip olmaması karşılaşılan güçlüklere örnek olarak verilebilir. 
Öğretmenlerin eğitim-öğretim sürecinde dersleri için kaçınılmaz olarak nitelendirdikleri öğretim teknolojileri konusundaki düşünceleri aşağıdaki tabloda görülmektedir.

Tablo 6. Vazgeçilmez olarak nitelendirilen öğretim teknolojileri

\begin{tabular}{|c|c|c|c|c|}
\hline Tema & Kategori & Kod & $\mathbf{N}$ & $f$ \\
\hline \multirow{10}{*}{ 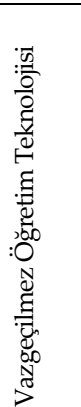 } & \multirow[t]{9}{*}{ Var } & Akıllı tahta & $\begin{array}{l}\text { Ö3,Ö4,Ö5,Ö6,Ö7,Ö8,Ö9,Ö11,Ö13,Ö14, } \\
\text { Ö16,Ö17,Ö18,Ö19,Ö20,Ö22,Ö23 }\end{array}$ & 17 \\
\hline & & Kara tahta & Ö1,Ö2,Ö6,Ö17,Ö18 & 5 \\
\hline & & Etkileşimli kitaplar & Ö11,Ö12,Ö14,Ö20 & 4 \\
\hline & & Ders kitabı & Ö8,Ö9,Ö14 & 3 \\
\hline & & Farklı yöntem-teknik-yazılımlar & Ö7,Ö24,Ö21 & 3 \\
\hline & & Bilgisayar & Ö5,Ö6 & 2 \\
\hline & & İnternet & Ö17 & 1 \\
\hline & & Projeksiyon & Ö8 & 1 \\
\hline & & Tablet & Ö19 & 1 \\
\hline & Yok & - & Ö10, Ö15 & 2 \\
\hline
\end{tabular}

Tablo 6' da görüleceği üzere, öğretmenler için kaçınılmaz olarak nitelendirilen öğretim teknolojilerinin başında akıllı tahta gelmektedir. Bu da akıllı tahtanın ne kadar çok benimsendiğini ve kullanıldığını hatta kaçınılmazlıkta yüzyıllardır kullanılan kara tahtanın önüne geçildiğini göstermektedir. Bunun yanında internet, ders kitaplanı, etkileşimli kitaplar, bilgisayar, tablet vs. şeklinde fikirler de belirtilmiştir. Ayrıca bu konu ile ilgili farklı bazı görüşlere aşağıda yer verilmiştir.

- Ö5. Bilgisayar, akıllı tahta özellikle geometri dersinin öğretiminde kesinlikle var olmast gereken öğretim teknolojileridir.

- Ö7. Bir matematik öğretmeni olarak akıll tahta, videolar, Geo gebra gibi önemli yazılımların kaçınılmaz olduğunu düşünüyorum.

- Ö18. Grafikler tablolar ve şekiller olabilir aslında zamandan tasarrufu să̆lar Fakat her okulda bunu kullanabilmek mümkün değil bu nedenle normal tahtadan ders işlemek ya da fotokopi kă̆gtlarından derse devam etmek zorunda kalıyoruz.

- Ö14. Internet olduğu sürece her türlü materyali akıll tahtadan bulabiliriz. Kitaplar ve ders kitapları da kaçınılmazdır.

Verilen cevaplar arasında öğretim teknolojilerini kaçınılmaz olarak bulmayan iki öğretmen bulunmaktadır. Ayrıca bu öğretmenlerin bulundukları okuldaki görev sürelerinin de 7 yıl ve üzeri olduğu göze çarpmaktadır. Uzayan görev süresinin yine öğretmenlerin geleneksel öğretim yöntemlerinden 
vazgeçemediğini veya bilinen eski yöntemlere olan yaklaşımların göstermektedir.

- Ö15. Matematik dersi için konularm bazllarında teknolojiden yararlanmak faydalı oluyor ama olmazsa olmaz değildir.

- Ö10. Hayır. Yoktur.

Tablo 7. Öğretmenlerin sıklıkla kullandıklan programlar

\begin{tabular}{|c|c|c|c|}
\hline Tema & Kod & $\mathbf{N}$ & $\mathbf{f}$ \\
\hline \multirow{10}{*}{ 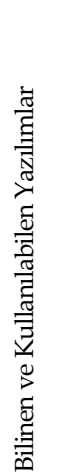 } & Word & $\begin{array}{l}\text { Ö1, Ö2, Ö3, Ö4, Ö5, Ö6, Ö8, Ö9, Ö10, Ö11, Ö12, Ö13, Ö14, Ö15, } \\
\text { Ö16, Ö17, Ö18, Ö19, Ö20, Ö21, Ö23, Ö24 }\end{array}$ & 22 \\
\hline & Excel & $\begin{array}{l}\text { Ö1, Ö2, Ö3, Ö6, Ö8, Ö9, Ö10, Ö11, Ö12, Ö13, Ö14, Ö15, Ö16, Ö17, } \\
\text { Ö18, Ö19, Ö20, Ö21, Ö24 }\end{array}$ & 19 \\
\hline & Powerpoint & $\begin{array}{l}\text { Ö1, Ö2, Ö3, Ö5, Ö6, Ö8, Ö9, Ö11, Ö12, Ö13, Ö15, Ö16, Ö17, Ö18, } \\
\text { Ö19, Ö20, Ö21 }\end{array}$ & 17 \\
\hline & Geogebra & Ö2, Ö14, Ö17, Ö18, Ö20, Ö21, Ö24 & 7 \\
\hline & Cabri & Ö7, Ö20 & 2 \\
\hline & Socrative & Ö7, Ö8 & 2 \\
\hline & Microsoft office & Ö22, Ö23 & 2 \\
\hline & Matletic & Ö7 & 1 \\
\hline & Mattup & Ö14 & 1 \\
\hline & Outlook & Ö16 & 1 \\
\hline
\end{tabular}

Tablo 7 incelendiğinde öğretmenlerin çoğunun Word, Excel ve Powerpoint' i kullanabildikleri, bunun yanında Geogebra, Cabri vs. farklı yazılımları da bilip kullanabildikleri görülmektedir. Öğretmenlerin teknoloji kullanabilme yeterliğine ve bireysel gelişime ilişkin görüşlerine Tablo $8^{\prime}$ de ve 9'da yer verilmiştir.

Tablo 8. Öğretmenlerin öğretim teknolojilerini kullanabilme düzeyleri

\begin{tabular}{|c|c|c|c|}
\hline Tema & Kod & $\mathbf{N}$ & 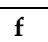 \\
\hline \multirow{3}{*}{ 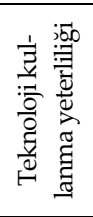 } & Yeterli, iyi & $\begin{array}{l}\text { Ö1, Ö2, Ö4, Ö7, Ö8, Ö9, Ö12, Ö16, Ö10, Ö11, } \\
\text { Ö15, Ö18, Ö20, Ö22, Ö23, }\end{array}$ & 15 \\
\hline & Orta düzey, geliştirilebilir & Ö3, Ö5, Ö6, Ö14, Ö19, Ö13, Ö17, Ö21 & 8 \\
\hline & Sinırlı & Ö24 & 1 \\
\hline
\end{tabular}

Tablo 8 ele alındığında ilköğretim matematik öğretmenlerinin öğretim teknolojilerini bilme ve kullanabilme konusunda çoğunlukla yeterli olduğu görülmektedir. 
- Ö5. Orta düzeyde Word, Powerpoint' i kullanabilirken Excel' de eksikliklerim bulunmaktadır. Bilgisayarı normal düzeyde kullanabilmekteyim. Çeşitli yazılım programlarm bilsem dersimi daha iyi anlatabilirim. Hazır yayınlardan yararlanıyorum. Yazılım programın çok iyi bilseydim kendi ders notlarımı hazırlayabilirdim. Yavaş kullandığımda vakit kaybı oluyor, bu nedenle hazır materyallerden yararlaniyorum.

- Ö7. Aldığım eğitim ve çabalar neticesinde öğretim teknolojilerinin birçoğuna hâkimim. Elimden geldiğince ve şartlar el verdikçe kullanmaya özen gösteriyorum.

- Ö8. Bilgisayar ve akıllı tahtayı iyi kullanirm. Programlardan ise Powerpoint ve Excel programina hakimim.

- Ö12. Teknoloji ile çok içli dışlı olduğum için son çıkan her türlü teknolojik ürünü takip ederek kullanmaya çalışıyorum.

- Ö13. Çoğunu kullanabilecek yeterlilikteyim ama öğretmenlere bu konu hakkında eğitim verilmesi gerektiğini düşünüyorum. Dersimde etkili olarak akıllı tahta kullanıyorum. Daha fazla öğretim teknolojisini kullanmak isterdim.

- Ö17. Ben gelenekselciyim ama geliştirilmemiz gerektiğini düşünüyorum.

- Ö19. Yeterli olmamakla birlikte orta seviyede olduğunu söyleyebilirim.

- Ö24. Hizmet içi eğitimden aldığım dersler kadar yeterliyim.

Tablo 9. Öğretmenlerin öğretim teknolojilerindeki bireysel gelişimleri

\begin{tabular}{|c|c|c|c|c|}
\hline Tema & Kategori & Kod & $\mathbf{N}$ & $f$ \\
\hline \multirow{9}{*}{ 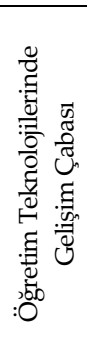 } & \multirow[t]{7}{*}{ Var } & UZEM & Ö5, Ö18, Ö21 & 3 \\
\hline & & Olabilir & Ö17, Ö22, Ö23 & 3 \\
\hline & & Kurs-sertifika-seminerler & Ö2, Ö5 & 2 \\
\hline & & Yeni programlar & Ö3, Ö20 & 2 \\
\hline & & Öğretim teknolojileri & Ö4, Ö24 & 2 \\
\hline & & İnternet & Ö6, Ö7 & 2 \\
\hline & & Hizmet içi kurs & Ö1 & 1 \\
\hline & \multirow[t]{2}{*}{ Yok } & Hayır & $\begin{array}{l}\text { Ö10, Ö13, Ö14, Ö15, Ö16, } \\
\text { Ö19, Ö11 }\end{array}$ & 7 \\
\hline & & Teknolojik yeterlilik & Ö8, Ö9, Ö12 & 3 \\
\hline
\end{tabular}

Tablo 9' da ilköğretim matematik öğretmenlerinin çoğunun öğretim teknolojileri konusunda gelişim çabası içinde olmadıkları görülmektedir. Bunun yanında hizmet içi eğitim ile kendilerini geliştirmeye çalışanların yanı sıra interneti takip ederek kendi çabalarıyla öğretim teknolojileri ile mesleklerinde ilerlemeye çalışanların da bulunduğu görülmektedir. Ayrca Ö5' in birden 
fazla koda değindiği görülmektedir. Konu ile ilgili bazı görüşlere aşağıda yer verilmiştir.

- Ö1. Evet, çabalıyorum kendi imkânlarım içerisinde üniversitenin verdiŏi sertifika programlarına katılmaya çalışıyorum. Seminer ve kurslar takviye niteliğindedir.

- $\quad$ Ö5. Bu konuda çabalarım var. Matematik yazılım programlarını öğrenmeye çalışıyorum. Bunun için üniversitelerde verilen sertifika programlarna katılmaktayım. Bunun dışında akıllı tahtayı daha etkili kullanabilmek için internette verilen çeşitli programları da takip etmekteyim. UZEM ile eksiklerimi gidermeye çalışıyorum. Bilgisayarı daha etkin nasıl kullanabileceŏimi araştırmakta ve çabalamaktayım.

- $\quad$ Ö7. Evet, mümkün olduğunca internetten sosyal medyadaki aktif üretim yapan sayfalardan, çevremdeki arkadaşlarımdan bir şeyler öğrenip öğretim teknolojisi konusunda kendimi daha da geliştirmeye çalışıyorum.

- Ö16. Hayır, böyle bir çabam yoktur.

- Ö18. Tabi kiözellikle Z-kitap uygulamalarını akıllı tahtaya yansıtma gibi çeşitli çalışmalarım oldu, fakat dediğim gibi okulun imkânları bu konuda yetersiz.

- Ö19. Düşünmüyorum, hayır.

- Ö15. Maalesef öyle bir çabam yok.

- Ö11. Eğitim sistemimizde olmamasına rağmen babamın da olmadığını düşünüyorum.

- Ö22. Gerekli çabaları gösteriyorum.

Öğretmenlerin teknolojiyi nerede ve nasıl kullandıklarına yönelik görüşlerine aşağıda yer verilmiştir.

\section{Tablo 10. Derste öğretim teknolojilerini kullanım aşamaları}

\begin{tabular}{|c|c|c|c|c|}
\hline Tema & Kategori & Kod & $\mathbf{N}$ & $f$ \\
\hline \multirow{11}{*}{ 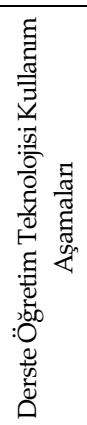 } & \multirow{10}{*}{ Kullaniyorum } & Soru çözümü & $\begin{array}{l}\text { Ö1, Ö2, Ö3, Ö4, Ö5, Ö6, Ö10, Ö14, } \\
\text { Ö19, Ö20, Ö21, Ö23 }\end{array}$ & 12 \\
\hline & & Ders başı & Ö1, Ö2, Ö3, Ö5, Ö6, Ö8, Ö14, Ö19 & 8 \\
\hline & & Şekil çizimi & Ö2, Ö3, Ö5, Ö14, Ö16, Ö20, Ö24 & 7 \\
\hline & & Dersin her aşamasında & Ö7, Ö11, Ö12, Ö13 & 4 \\
\hline & & Etkinliklerde & Ö1, Ö2, Ö5 & 3 \\
\hline & & Gündelik hayat & Ö4, Ö19 & 2 \\
\hline & & Konu anlatımı & Ö9, Ö15 & 2 \\
\hline & & Soyut konular & Ö6 & 1 \\
\hline & & Konu sonu & Ö17 & 1 \\
\hline & & Farklı materyal & Ö22 & 1 \\
\hline & Kullanmiyorum & İmkânsızlıklar & Ö18 & 1 \\
\hline
\end{tabular}


Tablo 10’ da görüldüğü gibi ilköğretim matematik öğretmenlerinin öğretim teknolojilerini genellikle soru çözümünde kullandıkları görülmektedir. Verimli ders işlemek için öğrencilerin görsel ve duyuşsal zekâlarını aktif kullanabilmeleri için faydalı olduğu belirtilmiştir. Ayrıca bu konu ile ilgili farklı bazı görüşlere aşağıda yer verilmiştir.

- Ö1. Dersin başında dikkat çekme, soru çözme aşamasında ve etkinliklerde kullaniyorum.

- Ö5. Dersimin bütün aşamasında kullanmaktayım. Dersin girişinde etkili anlatabilmek ve dikkat çekmek için görsel öğelere yer veririm. Soru çözümünde powerpoint' in hareketli animasyonlarından yararlanarak soru çözümünü daha anlaşılır cazibeli halde getiririm. Tekrar tekrar yazmamız gereken notları Word' den çıkararak az zamanda daha çok bilgi ve daha az enerji sarf etmiş olurum. Çizim ve görsel gerektiren konularda öğretim teknolojilerini kullanarak çizimlerin daha güzel olmasını sağlarmm.

- Ö7. Bence her aşamada kullanılabilir. Dersin başında öğrencileri güdülemek için ders esnasinda etkin katılımı sağlamak için dersin sonunda konuyu değiştirmek için kullanulabilir.

- Ö14. Genelde ders kitaplar ile konuyu anlatırm daha sonra soru çözümünde öğretim teknolojilerinin kullanırım öğrenilmesi zor öğrencinin yazmak için çok zaman harcayacağı konular ise akill tahta üzerinden anlatırım.

- Ö19. Öğrenciye sunuş yoluyla ettikten hemen sonra öğretim teknolojilerini kullanirum.

- Ö20. Soru çözümünde üç boyutlu görsellerde ve çizimi zor şekillerde zaman tasarrufu yapmak için kullanırım.

- Ö22. Derste farkl materyal kullanımı açısından değerlendirilebilir.

- Ö18. Eğitim sistemi öğrencinin fazla soru çözüp stnavda başarll olmasina dayanmaktadır. Bu nedenle çözebileceğimiz kadar çok soru çözdürüp öğretmeye çalışıyoruz. Okulun imkânlar yeni teknolojilerle uyumlu değil. Bu nedenle daha çok kitaplardan faydalanıyoruz.

\section{Tartışma ve Sonuç}

Çalışma doğrultusunda ilköğretim matematik öğretmenlerinin öğretim teknolojileri kavramından ne anladıkları, yazılım ve donanımlardan hangilerini 
bilip kullandıkları, öğretim teknolojilerindeki öz yeterlilikleri, öğretim teknolojilerini kullanım sırasında karşılaştıkları problemleri ve çözüm önerileri, öğretim teknolojilerini derslerinin hangi aşamasında kullandıkları gibi sorulara yanit aranmıştır.

Araştırma sonucu elde edilen bulgular ışığında ilköğretim matematik öğretmenlerinin çoğunlukla bildikleri öğretim teknolojileri arasında Word, PowerPoint ve Excel yer almaktadır. Seyrek olarak da Geogebra, Cabri, dinamik matematik yazılım programları mevcuttur. İköğretim matematik öğretmenlerinin birçoğu (Ö1, Ö2, Ö4, Ö7, Ö8, Ö9, Ö12, Ö16, Ö10, Ö11, Ö15, Ö18, Ö20, Ö22, Ö23) öğretim teknolojileri konusunda yeterli-iyi olduklarını düşünmektedir. Bunun yanında hizmet içi veya hizmet dışı eğitimler ile kendilerini geliştirmek isteyen ve öğretim teknolojileri hakkında kendilerini orta seviyede bulan (Ö3, Ö5, Ö6, Ö14, Ö19, Ö13, Ö17, Ö21) öğretmenler de mevcuttur. Ayrıca kendini hizmetiçi verilen eğitimler kadar yetkin olduğunu kabul eden (Ö24) bir öğretmen bulunmuştur. Belirtilen farklı düşüncelere sahip öğretmenlerin çalıştığı okuldaki görev sürelerinin veya cinsiyetlerinin bakış açllarında herhangibir değişikliğe neden olmadığı görülmekle birlikte görev süresi arttıkça öğretmenlerin herzaman kullandığı öğretim yöntem yaklaşımlarının kalıplaştığı, öğretimin gelenekselleştiği söyenebilir.

Korkmaz ve Korkmaz (2015)' in yaptığ etkileşimli tahta kullanımına yönelik olumlu görüşlerini içeren bulgular ile bu çalışmanın (Tablo 4) öğretim teknolojilerinin kullanımının olumlu etkisine yönelik bulgular paralellik göstermektedir. Attard ve Holmes (2020) teknolojik araç kullanımının, bireysel öğrenme ihtiyacındaki farkındalığı arttırdığını, dersin öğrenci merkezli ve uygulamaya yönelik olduğunu, matematikle etkileşimi arttırdığını; Niess (2005) teknoloji kullanımının, öğrencilerin anlama, öğrenme ve düşünme becerilerini daha üst düzeyde geliştirdiğini, kavram yanılgılarının daha az olduğunu belirtmişlerdir. Elde edilen bulgular bu çalışmanın bulguları (Tablo 4) ile paralellik göstermektedir.

Önal ve Çakır (2016) ile Brown (2017) ortaokul matematik öğretmenlerinin matematik öğretiminde kullandıkları bilişim teknolojileri hakkındaki görüşlerini incelemiştir. Araştırma bulguları (Tablo 2) öğretim teknolojisi kavramına yönelik öğretmen görüşleri ile paralellik göstermektedir. Ayrıca Brown (2017) öğretmeni teknoloji kullanmaya teşvik eden etkenlerin arasında müfredatın bunu gerekli kılmasını ve okul yöneticisinin desteğini vurgulamıştır. 
Çelik ve Kahyaoğlu (2007) yaptıkları çalışmada eğitimcilerin teknolojiye yönelik tutumlarının belirlenmesinin, olumsuz tutumlara yönelik gerekli tedbirlerin alınmasının eğitim-öğretime fayda sağlayacağını ifade etmişlerdir. Yapılan çalışmadaki (Tablo 9) öğretmenlerin öğretim teknolojilerindeki bireysel gelişimlerine yönelik sorulan soruda UZEM, kurs, sertifika, seminer, farklı öğretim teknolojileri, internet veya hizmetiçi kurslar ile öğretmenlerin bireysel gelişimlerine önem verdikleri ve gelişimin sağlanmasını istedikleri görülmektedir. Buna karşın 10 öğretmen teknolojik yetersizlikler nedeniyle bireysel gelişimlerinin gerçekleşemediğini ifade etmişlerdir. Ayrıca (Tablo 8) öğretmenlerin öğretim teknolojilerini kullanabilme düzeyleri ile ilgili sorulan soruda 15 öğretmen kendisini yeterli-iyi düzeyde bulurken kalan 9 öğretmen geliştirilmesi gerektiğini ve kendilerini sadece hizmetiçi verilen eğitimler kadar yeterli gördüklerini belirtmişlerdir.

Wachira ve Keengwe (2011) çalışmalarında eğitimde teknoloji kullanımının artması sonucu karşılaşılan zorluklara dikkat çekmektedir. İstatistiki olarak bilgisayar teknolojisine erişim artarken öğretimi artırmaya yönelik bilgisayar kullanımının düşük olduğunu belirtmişlerdir. Matematik öğretmenleri teknolojiye uyum açısından yazılım yetersizliği, teknik yetersizlikler, teknik destek yetersizliği gibi dışsal engellerin; zaman yetersizliği, yetersiz bilgi, yaşanan kaygı ve güven sorunu gibi içsel engellerin varlığından bahsetmektedir. Elde edilen bulgular yapılan çalışmada (Tablo 5) öğretim teknolojilerinin kullanımında yaşanan birçok sorun ve bulgular ile paralellik göstermektedir.

Hähkiöniemi (2013)'in çalışmasında; geleneksel ve öğretmen merkezli eğitim veren bir matematik öğretmeninin GeoGebra ile ilgili aktiviteleri içeren bir matematik öğretimi uygulaması yer almaktadır. Yazılımın kullanımı ile ders öğrenci merkezli bir sürece evrilmiş, öğrencilerin hemen hepsi düşünme sürecine ve derse katılmıştır. Ayrıca dersteki mevcut uğultuların kesilmesi gibi pek çok farklı olumlu etki de görülmüsstür. Buna karşın öğretmen bu uygulamanın çok zaman aldığını, yetiştirilmesi gereken konuların çok olduğunu ve materyal hazırlamanın da fazladan iş yükü oluşturduğunu belirtmiştir. Yıldızhan (2013) yapmış olduğu çalışmada etkileşimli tahtanın öğrenci motivasyonunu artırmasına rağmen öğretmenin kullanırken sorun yaşaması dâhilinde ders işleyişinin olumsuz etkilendiğini belirtmiştir. Öğreticilerin teknoloji ile ilgili teknik donanımlarının öğrenci başarısını doğrudan etkilediğini ifade etmiştir. Elde edilen tüm bu bulgular yapılan çalışmanın (Tablo 2, Tablo 4, Tablo 10) bulguları ile paralellik göstermektedir. 
Kurvinen, Kaila, Laakso ve Salakoski (2020)'nin uzun süreli teknoloji kullanımının aritmetik işlem hız düzeyi ve matematik öğrenme performansı üzerine yaptıkları araştırmanın bulgularına göre deney grubu lehine yüksek düzey öğrenme performansı istatistiksel olarak anlamlı bir farklılık göstermiştir. Aritmetik işlem hız düzeyi açısından ise gruplar arası istatistiksel olarak anlamlı bir farklılık görülmemiştir. Elde edilen bulgular (Tablo 3) öğretmenlerin kullanabildikleri yazılım ve donanımlar ile öğretim teknolojilerinin kullanımının etkileri (Tablo 4) beraber değerlendirildiğinde ilgili çalışmanın bulguları ile paralellik göstermektedir. Tablo 3'e göre kullanılabilen yazılım ve donanımlara az sayıda yanıt veren öğretmenlerin öğretim teknolojileri kullanımının etkileri hakkında faydasız veya önemsiz olarak yorumlarda bulunmaları bu duruma örnek olarak verilebilir.

\section{Öneriler}

- Gelişen teknolojiyle birlikte öğretmenlerin yeterli donanımlara sahip olabilmeleri için öğretim teknolojilerine yönelik hizmet içi eğitim ve kurs saatleri ve sayıları artırılabilir.

- Okullardaki etkileşimli tahtaların bakım-onarım ve güncellemeleri daha sık ve ilgili uzmanlara yaptırılmalıdır.

- Farkındalığı artırmak ve etkililiği sağlamak adına il veya ilçe geneli eğitimlerin yanı sıra okul bölgeleri kapsamında veya okulların kendi içinde kurslar ve seminerler daha sik olarak verilebilir.

- Müfredat hazırlanırken teknoloji kullanımını teşvik edici bir düzenleme yapilabilir.

- Okullardaki eksiklikler ve gereksinimler (Jeneratör, Antivirüs programı ile diğer yazılım ve donanımlar gibi) güncel ihtiyaçlar doğrultusunda tedarik edilmelidir.

- Öğretmenlere teknolojiyi nasıl kullanacaklarının yanı sıra teknolojiyi kullanarak nasıl öğreteceklerine yönelik eğitim verilebilir. 


\title{
EXTENDED ABSTRACT
}

\section{Elementary Mathematics Teachers' Perspectives on Instructional Technologies}

\author{
Ebru Korkmaz \\ Muş Alparslan University
}

At the present time, it is an important goal to improve students' mathematics competence in educational institutions regularly (Ball, 2003). In terms of achieving this goal, technology is seen as a necessity in learning and teaching mathematics for the development of students, because the rapid development of technology affects mathematics education (Leinwand and Burrill, 2002). In mathematics teaching, instructional technology is generally used in problem solving. Thus, learning experiences take place in a student-centered way. Certain technologies include various types of software and hardware.

It is necessary to use instructional technologies in education in accordance with today's conditions. The great responsibility belongs to the teachers who transfer the knowledge and guide students. The teacher should be able to use more than one tool from the blackboard to various software programs on the Internet (Tor and Erden, 2004). Teachers need to develop themselves and have a self-efficacy perception while following developing technology during education and training without being behind it (Oral, 2004). In this age, teachers should be able to use technology at an adequate level and apply these technologies at the desired level during the learning-teaching process (Gündüz and Odabaşı, 2004).

Students need an interesting, stimulating and enriching learning environment to improve themselves (Stronge, 2013, p.65). In 2001, with the carried out curriculum reform in China, students began to receive education in mathematics classes, which were prepared with a constructive method in richsourced, technological classes instead of traditional mathematics classes (Rui and Ngai-ying, 2013, p.356-358). In Turkey, with Fatih Project, it is seen in classes that technology began to be used more actively.

Traditional learning and activity-based learning approaches should be evaluated to determine teachers' feelings and thoughts about technology (Brown, 2017). So, the research is important for including teachers' thoughts, 
attitudes, problems and suggestions for solutions. In this context, the aim of the study is to determine the awareness of primary school mathematics teachers on instructional technologies.

In descriptive approach dimension, the case study design was used to examine the data obtained from the study. The reason for using this design in the study is that it enables many features of the situation to be studied in the least amount of time with detail (Yin, 2003; Çepni, 2007). The sample of the study consists of 24 elementary mathematics teachers working in a provincial center primary schools in Eastern Anatolia. In the study group, 11 of the teachers are men and 13 are women. In this study, a semi-structured interview form prepared by Baki, Aydın, Özpınar and Çalık (2009) was used as a data collection tool. Content analysis method was used in the analysis of the data with a descriptive approach (İşçi and Öztekin, 2013; Yıldırım and Şimşek, 2011). In addition, the analysis of the data was carried out in agreement with the two researchers beforehand. After the obtained data is arranged according to the codes and themes, direct quotations are included.

According to the findings of the research, it is seen that the teachers' responses to the question asked about what they understand from instructional technology emphasize the concepts such as tools and equipment used for effective education (EBA, FATIH Project, Interactive Board), adapting technology to education, addressing different senses, and modern teaching approaches. In the second question, it is stated that the most used instructional technologies by teachers are computers, internet, interactive board, video, blackboard, books and magazines. Primary school mathematics teachers stated that mostly instructional technologies facilitate education and training, save time, help to embody issues, are comfortable in terms of usefulness and provide effective teaching. In another question, as the difficulties experienced in the use of instructional technologies, teachers emphasize the problems such as lack of information, power outage, maintenance-control, internet, lack of material, out-of-purpose use, updating, virus, technology for acquisitions, software-hardware and students' not taking notes. Although the internet, textbooks, interactive books, computers, tablets are specified as indispensable teaching technologies, the blackboard in the second place of the list draws attention. It is stated that elementary mathematics teachers are mostly sufficient to know and use instructional technologies, and frequently used prog- 
rams are Word, Excel and Powerpoint. But it is seen that most of the elementary mathematics teachers are not in the development effort on instructional technologies. In addition, it is seen that some teachers try to improve themselves with in-service training, as well as some others try to progress in their profession with their own efforts by following the internet. Primary school mathematics teachers stated that they generally use instructional technologies in problem solving, besides, instructional technologies are used in different processes of the course such as the beginning of the course, figure drawing, activities, lecture, abstract topics, and the end of the subject.

In the findings obtained from the research, primary school mathematics teachers rarely use Geogebra, Cabri, dynamic mathematics software programs as the teaching technologies. Many elementary mathematics teachers think that they are sufficient-good on instructional technologies. In addition, there are teachers who want to improve themselves with in-service or some other trainings and find themselves at an intermediate level about instructional technologies. It is seen that the terms in schools or gender of the teachers who have different thoughts, do not cause any change in their perspectives. However, it can be said that as the duration of duty increases, the teaching method approaches that teachers always use become stereotypes and teaching becomes traditional.

In the study, it is seen that teachers give importance to their individual development and want to ensure development in instructional technologies with distant education, course, certificate, seminar, different instructional technologies, internet or in-service courses. In the context of these results, various suggestions are presented for decision makers and executives.

\section{Kaynakça / References}

Akkoyunlu, B. (1995). Bilgi teknolojilerinin okullarda kullanımı ve öğretmenlerin rolü. Hacettepe Üniversitesi Ĕ̆itim Fakültesi Dergisi, 11, 105-109.

Attard, C. ve Holmes, K. (2020). "It gives you that sense of hope": An exploration of technology use to mediate student engagement with mathematics. Heliyon, 6, e02945. https://doi.org/10.1016/j.heliyon.2019.

Baki, A., Aydın Yalçınkaya, H., Özpınar, İ. ve Çalık Uzun, S. (2009). İlköğretim matematik öğretmenleri ve öğretmen adaylarının öğretim teknolojilerine bakışlarının karşılaştırılması. Turkish Journal of Computer and Mathematics Education, 1(1), 65-83. 
Baki, A. (2002). Öğrenen ve öğretenler için bilgisayar destekli matematik. İstanbul: Ceren Yayıncılik.

Ball, D. L. (2003). Mathematical proficiency for all students, towards a strategic research and development program in mathematics education. Science and Technology Policy Institue, Rand Education.

Brown, J. P. (2017). Teachers' perspectives of changes in their practice during a technology in mathematics education research project. Teaching and Teacher Education, 64, 52-65. http://dx.doi.org/10.1016/j.tate.2017.01.022

Brown, J. (2017). Teacher's perception of technology use in the elementary mathematics classroom. Doctoral dissertation, Capella University, USA.

Çelik, H. C. ve Kahyaoğlu, M. (2007). İlköğretim öğretmen adaylarının teknolojiye yönelik tutumlarının kümeleme analizi. Türk Ĕ̆itim Bilimleri Dergisi, 5(4), 571-586.

Çepni, S. (2007). Araştırma ve proje çalışmalarına giriş. Trabzon: Celepler Matbacilik.

Demirel, Ö. (1993). Eğitim terimleri sözlü̆̆̈̈. Ankara: Usem Yayınları.

Gresalfi, M. S. ve Lester, F. (2009). What's worth knowing in mathematics? Constructivist Instruction: Success or Failure? (Eds. S. Tobias ve T. M. Duffy). New York: Routledge.

Gündüz, Ş. ve Odabaşı, F. (2004). Bilgi çağinda öğretmen adaylarinin eğitiminde öğretim teknolojileri ve materyal geliştirme dersinin önemi. The Turkish Online Journal of Educational Technology, 3(1), 43-49.

Güneş, F. (2014). Öğretim ilke ve yöntemleri. Ankara: Pegem Akademi Yayınları. Hähkiöniemi, M. (2013). Teacher's reflections on experimenting with technology-enriched inquiry-based mathematics teaching with a preplanned teaching unit. The Journal of Mathematical Behavior, 32, 295-308. http://dx.doi.org/10.1016/j.jmathb.2013.03.007

İşçi, S. ve Öztekin, Ö. (2013). Nitel veri analizi (Ed: S. Turan). Nitel Araştırma Desen ve Uygulama İçin Bir Rehber. Ankara: Nobel.

Kanold, T. D., Briars, D. ve Fennel, F. S. (2012) What principals need to know about teaching and learning mathematics. USA: Solution Tree.

Kaya, Z. (2006). Öğretim teknolojileri ve materyal geliştirme (2. Bask1). Ankara: Pegem A Yayıncilik.

Korkmaz, E. ve Korkmaz, C. (2015). Öğretmen adaylarının etkileşimli tahta kullanımına yönelik görüşleri. Mustafa Kemal Üniversitesi Sosyal Bilimler Enstitüsü Dergisi, 12(32), 477-497. 
Koşar, E., Yüksel, S., Özkılıç, R., Avcı, U., Alyaz, Y. ve Çiğdem, H. (2003). Öğretim teknolojileri ve materyal geliştirme. (2. Baskı). Ankara: Pegem A Yayınları.

Kurvinen, E., Kaila, E., Laakso, M-J. ve Salakoski, T. (2020). Long term effects on technology enhanced learning: the use of weekly digital lessons in mathematics. Informatics in Education, 19(1), 51-75. DOI: 10.15388/infedu.2020.04

Leinwand, S. ve Burrill, G. (2002). Improving mathematics education, resources for decision making. Washington, DC: National Academies Press.

McRel, M. (2012). What we know about mathematics teaching and learning. Solution Tree.

Miles, M.B. ve Huberman, A.M. (1994). Qualitative data analysis. (2nd Ed). Newbury Park, CA: Sage.

Niess, M. L. (2005). Preparing teachers to teach science and mathematics with teknology: Developing a technology pedagogical content knowledge. Teaching and Teacher Education, 21, 509-523. doi:10.1016/j.tate.2005.03.006

Oral, B. (2004). Öğretmen adaylarının internet kullanma durumları. XIII. Ulusal Eğitim Bilimleri Kurultayı. İnönü Üniversitesi, Eğitim Fakültesi, Malatya.

Ögüüt, H., Altun, A. A. ve Koçer, H. E. (2003). Bilgisayar destekli, internet erişimimli interaktif eğitim Cd'si ile e-eğitim. Turkish Online Journal of Educational Technology, 2(4), 67-75.

Önal, N. ve Çakır, H. (2016) Ortaokul matematik öğretmenlerinin matematik öğretiminde bilişim teknolojileri kullanımına ilişkin görüşleri. Mersin Üniversitesi Ĕ̆itim Fakültesi Dergisi, 12(1), 76-94.

Rui, D. ve Ngai-yin, W. (2013). The learning environment in the chinese mathematics classroom. How Chinese Teach Mathematics and Improve Teaching (Eds. Y. Li and R. Huang). New York: Routledge.

Stronge, J. H. (2013). Evaluating what good teachers do, eight research-based standards for assessing teacher excellence. New York: Routledge.

Tor, H. ve Erden, O. (2004). İlköğretim öğrencilerinin bilgi teknolojilerinden yararlanma düzeyleri üzerine bir araştırma. Turkish Online Journal of Educational Technology, 3(1), 120-130.

Turner, R. C. ve Carslon, L. (2003). Indexes of item-objective congruence for multidimensiona items. International Journal of Testing, 3(2), 163-171. 
Varol, N. (2002). Bilişim teknolojilerinin eğitim kurumlarında kullanımları ve eğitimcilerin rolü. Akademik Bilişim Konferansları, Selçuk Üniversitesi, Konya.

Wachira, P. ve Keengwe, J. (2011). Technology integration barriers: urban school mathematics teachers perspectives. J Sci Educ Technol, 20, 1725. DOI 10.1007/s10956-010-9230-y

Yıldırım, A. ve Şimşek, A. (2011). Sosyal bilimlerde nitel araştırma yöntemleri (8. Bask1). Ankara: Seçkin Yay.

Yıldızhan, Y., H. (2013) Temel eğitimde akıllı tahtanın matematik başarısına etkisi. Middle Eastern and African Journal of Educational Research, 5, 110121.

Yin, R. K. (2003). Case Study Research Design and Methods (Third Edition). London: New Delhi.

\section{EK 1}

1. Öğretim teknolojisi kavramından ne anlamaktasınız?

2. Aşağıdaki donanımlardan hangisi veya hangilerini kullanabilirsiniz?

- Bilgisayar

- Internet

- Akılli Tahta

- Yazilimlar

- Projeksiyon

- Tepegöz

- Episkop

- Kitap ve Dergi

- Video

- Karatahta

- Hesap Makinesi

- Ses Kayit Cihazı

3. Öğretim teknolojilerini kullanmanın faydalarına yönelik düşünceleriniz nelerdir?

4. Öğretim teknolojileri kullanımı konusunda karşılaşılan güçlükler nelerdir, okulunuza yönelik tavsiye ve öneriniz var mıdir? 
5. Kendi dersiniz için kaçınılmaz olarak nitelendirdiğiniz bir öğretim teknolojisi var midır?

6. Bilinen ve kullanılabilen yazılımlar (Word, Excel, Powerpoint vs.) nelerdir?

7. Öğretim teknolojilerini kullanma konusunda öz yeterliliğiniz nedir?

8. Öğretim teknolojilerinde gelişim hakkındaki çabalarınızın olduğunu düşünüyor musunuz?

9. Öğretim teknolojilerinin dersinizin hangi aşamasında kullanabilirsiniz? Neden?

\section{Kaynakça Bilgisi / Citation Information}

Korkmaz, E. (2020). İlköğretim matematik öğretmenlerinin öğretim teknolojilerine bakış açısı. OPUS-Uluslararası Toplum Araştırmaları Dergisi, 15(26), 4019-4045. DOI: 10.26466/opus.620980 